\title{
Identification of feline immunodeficiency virus subtype-B on St. Kitts, West Indies by quantitative PCR
}

\author{
Patrick J Kelly ${ }^{1}$, Ruey Stocking ${ }^{1}$, Dongya Gao ${ }^{2}$, Nikol Phillips ${ }^{1}$, Chuanling $\mathrm{Xu}^{1}$, Bernhard \\ Kaltenboeck ${ }^{2}$, Chengming Wang ${ }^{1}$ \\ ${ }^{1}$ Ross University School of Veterinary Medicine, Basseterre, St. Kitts, West Indies \\ ${ }^{2}$ Department of Pathobiology, College of Veterinary Medicine, Auburn University
}

\begin{abstract}
Introduction: Although antibodies to the feline immunodeficiency virus (FIV) have been detected by SNAP assay in cats from St. Kitts, there have been no molecular studies to further confirm the infection and determine the FIV subtypes present.

Methodology: Total nucleic acids were extracted from EDTA whole blood specimens from 35 cats, followed by quantitative fluorescence resonance energy transfer (FRET) PCR under a six-channel LightCycler 2.0 Instrument with Software version 4.1.

Results: Four of 11 stray cats (36 \%) but none of 24 owned cats were FIV positive by real-time PCR. High-resolution melting curve analysis indicated that all four positive cats were infected with FIV subtype-B.

Conclusions: This is the first molecular characterization of FIV subtypes on St. Kitts and the results confirm the high prevalence of FIV infection in stray cats on the island.
\end{abstract}

Key words: feline immunodeficiency virus; FRET PCR; Caribbean

J Infect Dev Ctries 2011; 5(6):480-483.

(Received 07 January 2011 - Accepted 21 March 2011)

Copyright (C) 2011 Kelly et al. This is an open-access article distributed under the Creative Commons Attribution License, which permits unrestricted use, distribution, and reproduction in any medium, provided the original work is properly cited.

\section{Introduction}

Feline immunodeficiency virus (FIV) was first discovered in 1986 [1] and has since been identified as the agent of feline AIDS worldwide [2-5]. FIV is an important cat pathogen and its prevalence varies among geographic locations, from $2 \%$ up to $30 \%$ [6]. About $15 \%$ of stray cats on St. Kitts are seropositive for FIV by the SNAP FIV/FeLV Combo Test [5]. Although this test has high sensitivity, it may produce false positive results [7] and it has been recommended that positive results are confirmed with other tests [8]. Further, the test does not enable the discrimination of the FIV subtypes that occur. Based on env gene polymorphisms [9-11], five wellcharacterized subtypes of FIV have been identified worldwide. The clinical significance of these subtypes is not clear but there is considerable genetic variation within and between the subtypes and this may play a role in vaccination efficacy.

Recently, a dual-emission fluorescence resonance energy transfer (FRET) real-time PCR has been described which detects FIV in blood and can differentiate the FIV subtypes [12]. In this report we describe the use of the FRET PCR to confirm the presence of FIV in cats on St Kitts and to establish which FIV subtypes occur.

\section{Methodology}

Cats and clinical specimens

All animal procedures in this study met the requirements of the Institutional Animal Care and Use Committee at Ross University School of Veterinary Medicine (RUSVM). In October and November 2010, venous whole blood samples were collected in EDTA from stray cats trapped in St. Kitts and owned cats that had been seen at the Ross University School of Veterinary Medicine Veterinary Teaching Hospital. The stray cats' blood samples were obtained from the cats in the student-run trapneuter-release program while these cats were under anesthesia for castration or ovariectomy. Blood from 35 cats (17 males) was analyzed; 11 of the cats were stray and 24 were owned cats.

Detection of antibodies against FIV by SNAP Feline Triple Test

FIV antibody, feline leukemia virus (FeLV) antigen, and feline heartworm (FHW) antigen in the plasma specimens of the cats were detected by the use of the SNAP Feline Triple Test (IDEXX Laboratories, Westbrook, Maine, USA) at the 
RUSVM diagnostic laboratory according to the manufacturer's instructions.

\section{Extraction of nucleic acids}

Total nucleic acid extraction was performed by glass fiber matrix binding and elution with the HighPure PCR Template Preparation Kit (Roche Molecular Biochemicals, Indianapolis, IN, USA) as described [13]. For each sample, $200 \mu 1$ EDTA-whole blood was mixed with an equal volume of binding buffer [6 M guanidine- $\mathrm{HCl}, 10 \mathrm{mM}$ urea, $20 \%$ (v/v) Triton X-100, $10 \mathrm{mM}$ Tris-HCl, $\mathrm{pH} 4.4]$, and eluted in $150 \mu 1$ elution buffer.

\section{FRET PCR and melting curve analysis}

The design of the primers and probes, real-time PCR platform, and high-resolution melting curve analysis were performed as described [12-14]. The FIV copy number was determined by FRET-PCR performed in a six-channel LightCycler 2.0 Instrument with Software version 4.1 (Roche Molecular Biochemicals, Indianapolis, IN, USA). The PCR amplicon represents the first 164 nucleotides of the gag coding sequence. While FIV subtyping is traditionally based on the env gene polymorphisms, it has been recently demonstrated that the phylogenetic trees constructed from the gag gene and env gene reveal the same subtype classification $[15,16]$. The FIV capsid (gag) gene sequences are more conserved than those of the envelope (env) gene. The higher similarities of FIV gag gene among different subtypes allowed the designing of fully conserved sets of primers to amplify all FIV strains. The primers (upstream primer: 5'-ATG GGG AAY GGA CAG GGG CGA GA-3'; downstream primer: 5'-TCT GGT ATR TCA CCA GGT TCT CGT CCT GTA-3') were designed to amplify all reported FIV strains. Since FIV subtype $D$ is substantially different from other subtypes, the probes F1-D (6-FAM-TAC TTC GTT GTC CCG TAC CTA CAG CA-Phosphate) and F6D (CCA TCT AAA ATT TCC TTC CCC GAA CTT C-CY5.5, $\lambda=705 \mathrm{~nm}$ ) were used to detect FIV subtype-D. Probes F1-ABCE (6-FAM-TAC TCT TSS CCC CTA CTC CTA CAG CA-6-FAM) and F4-ABCE (LC Red 640-CAT TAC TAC ATC TYT TWA TGG CCA YTT TCC A-Phosphate, $\lambda=640$ $\mathrm{nm})$ were used to detect subtypes A, B, C, and E [12].

Nucleotide fragments representing the amplicons of all FIV subtypes were synthesized and inserted in the pIDTSMART cloning Vector (Integrated DNA Technologies, Coralville, IA, USA). The plasmid was restricted with HindIII (Promega, Madison, WI, USA) and quantified by PicoGreen DNA fluorescence assay (Molecular Probes, Eugene, OR, USA) for preparation of quantitative standards. The melting curve for the annealing of the PCR product was determined by monitoring the fluorescence from $37^{\circ} \mathrm{C}$ to $85^{\circ} \mathrm{C}$, and the temperature transition rate of $0.2^{\circ} \mathrm{C}$ per second was applied [12,14]. The fluorescence ratios F4/F1 and F6/F1 were analyzed, and the negative first derivatives of $F 4 / F 1$ and F6/F1 were evaluated for determination of probe $T_{\mathrm{m}}$.

\section{Results}

FeLV antigen and feline heartworm FHW antigen were not detected in these 11 stray cats by the SNAP Feline Triple Test. Four male stray cats $(4 / 11$, $36 \%$ ) were FIV positive by the SNAP Feline Triple Test and the quantitative FRET-PCR. All owned cats were negative by quantitative PCR and by the SNAP Feline Triple Test. The gag copies per ml EDTA whole blood for these four FIV-infected cats in quantitative PCR were $300,140,20$ and 20 respectively. Following the completion of PCR, the melting temperature $(\mathrm{Tm})$ of probe hybridization to the targets was determined by melting curve analysis as the peak of the second derivative of the fluorescence released. Based on the PCR amplification efficiencies and the $T m$ conditions as demonstrated during PCR amplification and melting curve analysis of synthesized amplicons of FIV subtypes A, B, C, D and E [12], all four FIV isolates from St. Kitts were recognized as FIV subtype-B. The amplification curve for FIV subtype-B was less vigorous than for subtypes $A$ and $C$ in the fluorescence $\mathrm{F} 4 / \mathrm{F} 1$ channel [12], and no peak appeared in the fluorescence channel F6/F1. In channel F4/F1, all four FIV isolates from St. Kitts show an identical $T m 54^{\circ} \mathrm{C}$, confirmed to be subtype$\mathrm{B}$ as established using the synthesized amplicons of FIV subtypes [12].

\section{Discussion}

Based on sequence differences in a hypervariable region of the envelope (env) gene, FIV isolates are characterized into five subtypes A, B, C, D, and E worldwide. Subtypes A and B predominate in the USA and Canada while $\mathrm{B}, \mathrm{C}$ and $\mathrm{D}$ predominate in Asian countries and subtypes A, B, C and D have been identified in European cats. Subtype A has been described in Australia and Africa and subtypes $\mathrm{B}$ and $\mathrm{E}$ have been found in South Africa [6]. Our study shows that subtype-B occurs on St. Kitts. 
Further, we have confirmed an earlier study [5] showing that FIV occurs on the island and is present at a high level $(4 / 11 ; 36 \%)$ in stray cats, which is also the case in other Caribbean islands, for example Grenada (29\%) [17]. Stray cats are common on St. Kitts [18] and thus present a reservoir of infection for the owned cats on the island where FIV is rare $(0 \%$; 0/24). A leukocyte-containing whole blood specimen, rather than plasma or serum, is required to extract nucleic acid for PCR amplification of the FIV target. In this study, the viral loads in four FIV-positive stray cats were lower than reported (12), and FIV infection was not observed in owned cats. A large sample size of feline specimens will improve the investigation of the epidemiology and infectious burdens of FIV in stray and owned cats.

Although a killed vaccine against FIV infection is available, it contains subtypes $\mathrm{A}$ and $\mathrm{D}$ and provides questionable protection against infections with the FIV subtype-B [6]. Until the efficacy of the vaccine is more clearly detailed, owned cats should not be allowed to come into contact with strays. Further, as FIV can be transmitted by bite wounds [19] and male cats are more likely to show territorial aggression and be involved in fights [20], the current neutering programs on St. Kitts should be continued and FIV infected animals need to be either neutered to reduce mating and aggression or removed from the population [21].

\section{Acknowledgments}

The authors gratefully acknowledge the financial support and diagnostic services from Ross University School of Veterinary Medicine.

\section{References}

1. Pedersen NC, Ho EW, Brown ML, Yamamoto JK (1987) Isolation of a T-lymphotropic virus from domestic cats with an immunodeficiency-like syndrome. Science 235: 790-793.

2. Gleich SE, Krieger S, Hartmann K (2009) Prevalence of feline immunodeficiency virus and feline leukaemia virus among client-owned cats and risk factors for infection in Germany. J Feline Med Surg 11: 985-992.

3. Kawaguchi Y, Norimine J, Miyazawa T, Kai C, Mikami T (1992) Sequences within the feline immunodeficiency virus long terminal repeat that regulate gene expression and respond to activation by feline herpesvirus type 1. Virology 190: 465-468.

4. Novak JM, Crawford PC, Kolenda-Roberts HM, Johnson CM, Mergia A (2007) Viral gene expression and provirus load of Orf-A defective FIV in lymphoid tissues and lymphocyte subpopulations of neonatal cats during acute and chronic infections. Virus Res 130: 110-120.

5. Kelly PJ, Moura L, Miller T, Thurk J, Perreault N, Weil A, Maggio R, Lucas H, Breitschwerdt E (2010) Feline immunodeficiency virus, feline leukemia virus and
Bartonella species in stray cats on St Kitts, West Indies. J Feline Med Surg 12: 447-450.

6. Sellon RK and Hartmann K (2006). Feline Immunodeficiency Virus Infection. In Greene CE, editor. Infectious Diseases of the dogs and Cats. Philadelphia: W.B. Saunders Co. 131-143.

7. Sand C, Englert T, Egberink H, Lutz H, Hartmann K (2010) Evaluation of a new in-clinic test system to detect feline immunodeficiency virus and feline leukemia virus infection. Vet Clin Pathol 39: 210-214.

8. Hartmann K, Werner RM, Egberink H, Jarrett O (2001) Comparison of six in-house tests for the rapid diagnosis of feline immunodeficiency and feline leukaemia virus infections. Vet Rec 149: 317-320.

9. Pancino G, Fossati I, Chappey C, Castelot S, Hurtrel B, Moraillon A, Klatzmann D, Sonigo P (1993) Structure and variations of feline immunodeficiency virus envelope glycoproteins. Virology 192: 659-662.

10. Pancino G, Castelot S, Sonigo P (1995) Differences in feline immunodeficiency virus host cell range correlate with envelope fusogenic properties. Virology 206: 796-806.

11. Verschoor EJ, Boven LA, Blaak H, van Vliet AL, Horzinek MC, Ronde A (1995) A single mutation within the V3 envelope neutralization domain of feline immunodeficiency virus determines its tropism for CRFK cells. J Virol 69: 4752-4757.

12. Wang C, Johnson CM, Ahluwalia SK, Chowdhury E, Li Y, Gao D, Poudel A, Rahman KS, Kaltenboeck B (2010) Dualemission fluorescence resonance energy transfer (FRET) real-time PCR differentiates feline immunodeficiency virus subtypes and discriminates infected from vaccinated cats. J Clin Microbiol 48: 1667-1672.

13. DeGraves FJ, Gao D, Hehnen HR, Schlapp T, Kaltenboeck B (2003) Quantitative detection of Chlamydia psittaci and C. pecorum by high-sensitivity real-time PCR reveals high prevalence of vaginal infection in cattle. J Clin Microbiol 41: 1726-1729.

14. Li Y, Wang C, Allen KE, Little SE, Ahluwalia SK, Gao D, Macintire DK, Blagburn BL, Kaltenboeck B (2008) Diagnosis of canine Hepatozoon spp. infection by quantitative PCR._Vet Parasitol 157: 50-58.

15. Steinrigl A, Klein D (2003) Phylogenetic analysis of feline immunodeficiency virus in Central Europe: a prerequisite for vaccination and molecular diagnostics J Gen Virol 84: 13011307.

16. Weaver EA, Collisson EW, Slater M, Zhu G (2004) Phylogenetic analyses of Texas isolates indicate an evolving subtype of the clade B feline immunodeficiency viruses. J Virol 78: 2158-2163.

17. Mofya S, Sharma R, Stone D, Hariharan H, Pensick A, Baffa A, Sakari J, Doherty D (2008) Seroepidemiological study of Feline Leukemia Virus and Feline Immunodeficiency Virus in feral and domestic cats in Grenada. West Indian Veterinary Journal 8: 18-22.

18. Moura L, Miller T, Thurk J, Kelly PJ, Krecek T (2007) Animal ownership and attitudes to feral cats on St Kitts, West Indies. West Indian Veterinary Journal 7: 72-74.

19. Yamamoto JK, Hansen H, Ho EW, Morishita TY, Okuda T, Sawa TR, Nakamura RM, Pedersen NC (1989) Epidemiologic and clinical aspects of feline immunodeficiency virus infection in cats from the continental United States and Canada and possible mode of transmission. J Am Vet Med Assoc 194: 213-220. 
20. Levy J, Crawford C, Hartmann K, Hofmann-Lehmann R, Little S, Sundahl E, Thayer V (2008) 2008 American Association of Feline Practitioners' feline retrovirus management guidelines. J Feline Med Surg 10: 300-316.

21. Hosie MJ, Addie D, Belák S, Boucraut-Baralon C, Egberink H, Frymus T, Gruffydd-Jones T, Hartmann K, Lloret A, Lutz H, Marsilio F, Pennisi MG, Radford AD, Thiry E, Truyen U, Horzinek MC (2009) Feline immunodeficiency. ABCD guidelines on prevention and management. J Feline Med Surg 11: 575-84.

\section{Corresponding author}

Chengming Wang

Ross University School of Veterinary Medicine

PO Box 334

Basseterre, St. Kitts, 00265, West Indies

Telephone: 869-465-4161

Fax: 869-465-1203

Email: chwang@rossvet.edu.kn

Conflict of interest: No conflict of interest is declared. 